\title{
The real part of the refractive indices and effective densities for chemically segregated ambient aerosols in Guangzhou measured by a single-particle aerosol mass spectrometer
}

\author{
Guohua Zhang ${ }^{1}$, Xinhui Bi ${ }^{1}$, Ning Qiu ${ }^{2}$, Bingxue Han ${ }^{1}$, Qinhao Lin ${ }^{1,3}$, Long Peng ${ }^{1,3}$, Duohong Chen ${ }^{4}$, \\ Xinming Wang ${ }^{1}$, Ping'an Peng ${ }^{1}$, Guoying Sheng ${ }^{1}$, and Zhen Zhou ${ }^{5}$ \\ ${ }^{1}$ State Key Laboratory of Organic Geochemistry and Guangdong Key Laboratory of Environmental Resources Utilization and \\ Protection, Guangzhou Institute of Geochemistry, Chinese Academy of Sciences, Guangzhou 510640, PR China \\ ${ }^{2}$ South China Sea Institute of Oceanology, Chinese Academy of Sciences, Guangzhou 510301, PR China \\ ${ }^{3}$ Graduate University of Chinese Academy of Sciences, Beijing 100049, PR China \\ ${ }^{4}$ State Environmental Protection Key Laboratory of Regional Air Quality Monitoring, Guangdong Environmental Monitoring \\ Center, Guangzhou 510308, PR China \\ ${ }^{5}$ Atmospheric Environment Institute of Safety and Pollution Control, Jinan University, Guangzhou 510632, PR China
}

Correspondence to: Xinhui Bi (bixh@gig.ac.cn)

Received: 29 September 2015 - Published in Atmos. Chem. Phys. Discuss.: 10 December 2015

Revised: 15 February 2016 - Accepted: 22 February 2016 - Published: 3 March 2016

\begin{abstract}
Knowledge on the microphysical properties of atmospheric aerosols is essential to better evaluate their radiative forcing. This paper presents an estimate of the real part of the refractive indices $(n)$ and effective densities $\left(\rho_{\text {eff }}\right)$ of chemically segregated atmospheric aerosols in Guangzhou, China. Vacuum aerodynamic diameter, chemical compositions, and light-scattering intensities of individual particles were simultaneously measured by a single-particle aerosol mass spectrometer (SPAMS) during the fall of 2012. On the basis of Mie theory, $n$ at a wavelength of $532 \mathrm{~nm}$ and $\rho_{\text {eff }}$ were estimated for 17 particle types in four categories: organics (OC), elemental carbon (EC), internally mixed EC and OC (ECOC), and Metal-rich. The results indicate the presence of spherical or nearly spherical shapes for the majority of particle types, whose partial scattering cross-section versus sizes were well fitted to Mie theoretical modeling results. While sharing $n$ in a narrow range (1.47-1.53), majority of particle types exhibited a wide range of $\rho_{\text {eff }}(0.87-$ $\left.1.51 \mathrm{~g} \mathrm{~cm}^{-3}\right)$. The OC group is associated with the lowest $\rho_{\text {eff }}\left(0.87-1.07 \mathrm{~g} \mathrm{~cm}^{-3}\right)$, and the Metal-rich group with the highest ones $\left(1.29-1.51 \mathrm{~g} \mathrm{~cm}^{-3}\right)$. It is noteworthy that a specific EC type exhibits a complex scattering curve versus size due to the presence of both compact and irregularly shaped particles. Overall, the results on the detailed relationship be-
\end{abstract}

tween physical and chemical properties benefits future research on the impact of aerosols on visibility and climate.

\section{Introduction}

Aerosols represent the largest uncertainty in estimating radiative forcing, through strongly affecting the energy balance of the Earth by scattering and/or absorbing solar radiation (IPCC, 2007; Jacobson, 2001; Ramanathan and Carmichael, 2008), and cloud formation (Jacobson, 2006; Rosenfeld et al., 2008). They also strongly affect visibility, causing severe haze problems in polluted regions (Wu et al., 2005; Zhang et al., 2010). Submicron particles commonly make up the majority of total aerosol mass in polluted urban atmospheres (Tao et al., 2014; Shi et al., 2014), and contribute to the majority of light scattering and absorption (Seinfeld and Pandis, 2006; Bond and Bergstrom, 2006).

Optical properties of atmospheric aerosols are sensitive to their physical (e.g., size, density, and morphology) and chemical properties (Moffet and Prather, 2009; Moffet et al., 2008; Raut et al., 2009). Aerosols are generally internally mixed, composed of various compounds, and therefore uncertainties are inevitable when modeling their effects 
based on the assumption that they are composed of several individual species that are externally mixed (Sullivan and Prather, 2005). Therefore, knowledge of the direct link between aerosol optical properties and mixing state is required to accurately predict their radiative forcing (Bauer et al., 2013). However, the chemical composition, size, optical property, shape, and density of aerosols are generally measured by independent analytical techniques, which may inevitably introduce uncertainties when establishing their relationships.

Efforts have been made to embed light-scattering measurements into aerosol mass spectrometry in order to simultaneously retrieve as much information as possible for a single particle (Murphy et al., 2004; Moffet and Prather, 2005; Cross et al., 2007). For example, Moffet et al. (2008) have successfully retrieved the real part of the refractive indices $(n)$ and effective densities ( $\left.\rho_{\text {eff }}\right)$ for various particle types in the atmosphere of California and Mexico City, which have served as important parameters for optical properties in global climate models (Moffet and Prather, 2009; Ghan and Schwartz, 2007).

The relationship between the mixing state and optical properties of ambient aerosols in China is still not well understood. Previous studies in China typically performed model calculations, mostly based on the assumption of particle mixing state (Ma et al., 2012; Tao et al., 2014), and no previous direct measurements are available. Herein, we applied a real-time single-particle aerosol mass spectrometer (SPAMS) with embedded light-scattering measurements to explore the microphysical properties (i.e., $n$ and $\rho_{\text {eff }}$ ) of individual particle types as a function of chemical compositions in Guangzhou, China. The $n$ and $\rho_{\text {eff }}$ of the particle types, assumed to be spherical and homogeneously mixed, could be retrieved from the best fitting between the measured lightscattering signals and Mie theoretical modeling results.

\section{Materials and methods}

\subsection{Single-particle measurements and data analysis}

Single-particle measurements were carried out at an urban site in Guangzhou (Bi et al., 2011) from 13 October to 29 November 2012, using a SPAMS developed by Hexin Analytical Instrument Co., Ltd (Guangzhou, China). Temporal profiles of local meteorological parameters, including solar radiation, temperature, relative humidity, wind direction, wind speed, and air quality parameters (i.e., $\mathrm{NO}_{x}, \mathrm{SO}_{2}$, $\mathrm{O}_{3}, \mathrm{PM}_{1}$ ) are shown in Fig. $\mathrm{S} 1$ in the Supplement. Prior to particle detection, aerosols were dried by a diffusion dryer (Topas GmbH, series 570), because water associated with aerosols may be evaporated in the aerodynamic lens in the SPAMS, leading to complex sizing and mass spectral characteristics (Zelenyuk et al., 2006). Details of the particle detection method of SPAMS can be found elsewhere (Li et al.,
2011). Briefly, an ambient particle is introduced into SPAMS through a critical orifice, then focused and accelerated to a specific velocity in an aerodynamic lens. The velocity is then determined by two continuous diode Nd:YAG laser beams $(532 \mathrm{~nm})$ in the downstream sizing region. The experimental light-scattering signals (LSS) of the laser beams at $532 \mathrm{~nm}$ with scattering angle ranging from 5.1 to $174.9^{\circ}$ collected by an ellipsoidal reflector are measured by a photomultiplier tube. Since only a part of total scattered light is measured, the LSS actually corresponds to the partial scattering crosssection (PSCS). The determined velocity is used to trigger a pulsed laser $(266 \mathrm{~nm})$ to desorp/ionize the particle. The produced positive and negative fragments generated by the pulsed laser are also recorded with the velocity. The velocity is related to vacuum aerodynamic diameters $\left(d_{\mathrm{va}}\right)$ using a calibration curve, created from the measured velocities of series of polystyrene latex spheres (PSL, Nanosphere Size Standards, Duke Scientific Corp., Palo Alto) with pre-defined sizes.

A total of approximately 3500000 single-particle mass spectra were characterized and statistically analyzed in the present study. The analysis mainly covered particles with $d_{\mathrm{va}}$ between 0.1 and $1.6 \mu \mathrm{m}$. An adaptive resonance theory based neural network algorithm (ART-2a) was applied to cluster individual particles based on the presence and intensities of ion peaks in single-particle mass spectra (Song et al., 1999), with a vigilance factor of 0.7 , learning rate of 0.05 , and 20 iterations. By manually merging similar clusters, 17 major particle types with distinct chemical patterns were obtained, representing $\sim 95 \%$ of the population of the detected particles.

\subsection{Retrieving $n$ and $\rho_{\text {eff }}$ with Mie fitting model}

A large data set, including size, chemical composition, and the LSS of each particle at wavelength of $532 \mathrm{~nm}$, was collected by the SPAMS. Scattering by spherical submicron particles can be well described by Mie theory (Bohren and Huffman, 1981). In Mie theory, the refractive index is given by $m=n+i \cdot k$ with $n$ and $k$ being real constants and $i=-1^{1 / 2}$. However, only PSCS for particles were measured and thus only the real part of the refractive index (i.e., $n$ ) is focused in the following calculation. Based on the theory, $n$ and $\rho_{\text {eff }}$ can be derived for chemically distinct particle types obtained from the clustering analysis, according to the methodology developed by Moffet and Prather (2005).

The methodology is briefly summarized herein. Firstly, theoretical response (i.e., PSCS) is firstly compared with the LSS measured by SPAMS from PSL particles with sizes ranging from 150 to $2000 \mathrm{~nm}$. Then a calibration curve is constructed to transform the LSS (at the 90th percentiles, i.e., upper limit) measured by SPAMS to the PSCS, enabling a quantitative comparison between the measured and theoretical PSCS. Before performing the scattering calculation, the detected particles were grouped into 17 particle types on the basis of chemical compositions. Finally, a series of $n$ and $\rho_{\text {eff }}$ 
were used as input in the Mie theoretical calculation to find the best fit (i.e., a global minimum of the sum of squares due to error, SSE) between the measured and theoretical PSCS with the least square method, thus enabling the estimation of $n$ and $\rho_{\text {eff }}$. A detailed description of the methodology for the SPAMS and the results of the test on the known aerosol samples (i.e., $\mathrm{NaNO}_{3}$ and $\left.\left(\mathrm{NH}_{4}\right)_{2} \mathrm{SO}_{4}\right)$ is available in our previous publication (Zhang et al., 2015a). During the sizing detection, the particles diverge from each other and thus a wide range of light-scattering intensities from nearly zero to some upper limit are obtained for similar particles. This is due to the uneven distribution of laser beam energy, and also to the relative position of the laser beam and the pathway of particles. In order to avoid the effect of high-intensity outliers in our study, we used only LSS that lie at the 90th percentiles of the collected data in $20 \mathrm{~nm}$ size bins, regarding the upper $10 \%$ as outliers. Satisfactory results were obtained for calibration on PSL and test on $\mathrm{NaNO}_{3}$ and $\left(\mathrm{NH}_{4}\right)_{2} \mathrm{SO}_{4}$. Other percentile data (such as values at 95th and 99th percentiles) was also tested; however, the PSL calibration cannot be improved, which is possibly attributable to the outliers lying at the upper $10 \%$ percentile of the collected data. Therefore, we use 90th percentiles of LSS as the upper-limit values in the following discussion.

The calibration curve is provided in Fig. S2 to show the relationship between the experimental LSS and the theoretical PSCS ( $\left.R_{\text {theory }}\right)$. The modeling uncertainties for the retrieved $n$ and $\rho_{\text {eff }}$ of each particle type were estimated through a sensitivity analysis (Moffet et al., 2008). The raw experimental LSS were transformed using the retrieved calibration functions at the upper and lower $95 \%$ confidence bounds to obtain the absolute uncertainties for the $n$ and $\rho_{\text {eff }}$. The results show that the uncertainties were in the range of 2-5 and 9$20 \%$ for the retrieved $n$ and $\rho_{\text {eff }}$, respectively. The retrieved $n$ in our case should be defined as the equivalent refractive index for spherical, homogeneously internally mixed particles with the same bulk scattering properties as the actual particles. This assumption is similarly applied for aerosol components when trying to obtain their optical properties and/or radiative forcing (Moffet et al., 2008; Myhre et al., 1998).

\section{Results and discussion}

The 17 particle types, resulted from ART-2a clustering, are in four categories of similar chemical characteristics, namely: organics (OC), elemental carbon (EC), internally mixed elemental carbon and organics (ECOC), and Metal-rich. The majority of the single-particle types and their mass spectra throughout the study were similar to those described in our previous publication (Zhang et al., 2015b). Their mass spectra are provided in Fig. S3 and also described in the Supplement. It is pointed that assuming negligible absorption for the internally mixed EC particle types (including EC and ECOC group) might introduce uncertainties for the estimation of $n$.

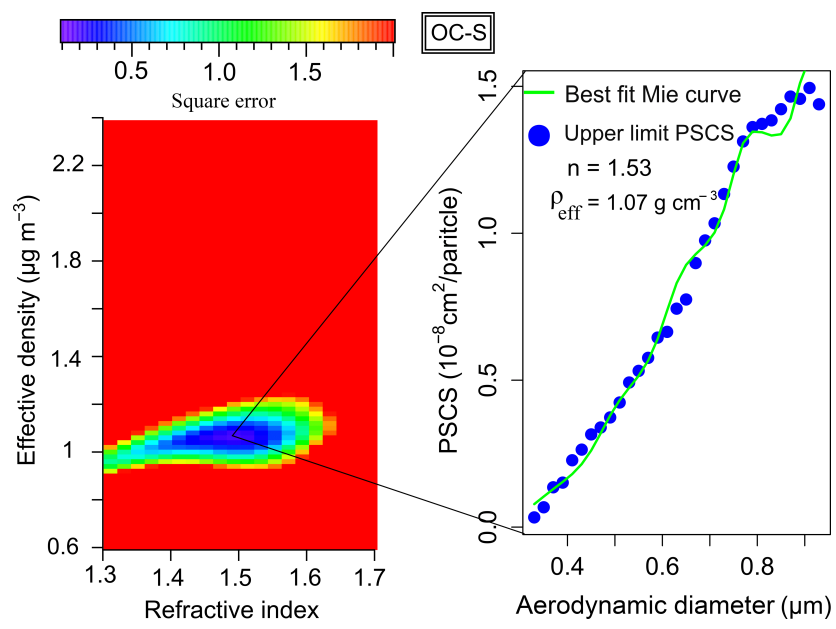

Figure 1. SSE distribution of fitting between measured and theoretical PSCS as a function of $n$ and $\rho_{\text {eff }}$ (left), and measured and best fit theoretical PSCS as a function of $d_{\mathrm{va}}$ (right) for OC-S.

Using Mie theory core-shell modeling, the scattering of the internally mixed EC particle types can be reasonably well described with the coating $(<100 \mathrm{~nm})$ refractive index as an input (Moffet and Prather, 2009). Therefore, the retrieved $n$ for the internally mixed EC particle types in the present study could be used to represent the coating refractive indices.

\subsection{Retrieved $n$ and $\rho_{\text {eff }}$ for chemically segregated aerosols}

To retrieve $\rho_{\text {eff }}$ for the ambient aerosols, it is assumed that $n$ falls between 1.3 and $1.7(\Delta n=0.01)$, and $\rho_{\text {eff }}$ fell from $<1$ to $\sim 2.5 \mathrm{~g} \mathrm{~cm}^{-3}$ which roughly corresponds to the range from hydrocarbons $\left(<1 \mathrm{~g} \mathrm{~cm}^{-3}\right)$ to inorganic salt (e.g., $2.17 \mathrm{~g} \mathrm{~cm}^{-3}$ for $\mathrm{NaCl}$ ), covering the range of $n$ and particle densities observed for the majority of ambient aerosols, as summarized in Hand and Kreidenweis (2002).

\subsubsection{OC Group}

The OC group was characterized by three organic-rich particle types, including organics dominantly internally mixed with sulfate and limited nitrate (OC-S), organics internally mixed with both sulfate and nitrate (OC-SN), and high-mass OC (HMOC). Figure 1 (left panel) exhibits the SSE between measured and theoretical PSCS varying with the two variables $n$ and $\rho_{\text {eff }}$ for OC-S particle type. The minimum SSE for OC-S particles was obtained when $n$ and $\rho_{\text {eff }}$ were 1.53 and $1.07 \mathrm{~g} \mathrm{~cm}^{-3}$, respectively (Table 1 ). The scattering curve and the raw scattering data measured for this particle type were compared to those predicted by Mie theory (Fig. 1, right panel). Strong correlation and consistent trend between the measured and theoretical PSCS indicates the existence of spherical or nearly spherical OC-S particles. It is noted that some particles exhibited negative PSCS, which is attributed 
Table 1. Retrieved $n$ and $\rho_{\text {eff }}$, and the fractional contribution of 17 particle types detected during the sampling period.

\begin{tabular}{llrrrr}
\hline Particle categories & Particle types & $n$ & $\rho_{\text {eff }}$ & $\mathrm{Nf}^{\mathrm{b}}(\%)$ & $R^{2 \mathrm{c}}$ \\
\hline ECOC & K-S & $1.49(3 \%)$ & $1.25(17 \%)$ & 10.2 & 0.97 \\
& K-SN & $1.49(4 \%)$ & $1.21(17 \%)$ & 21.0 & 0.97 \\
& K-N & $1.49(1 \%)$ & $1.43(14 \%)$ & 3.1 & 0.95 \\
& ECOC-S & $1.49(2 \%)$ & $1.27(16 \%)$ & 7.0 & 0.93 \\
& ECOC-SN & $1.47(3 \%)$ & $1.25(17 \%)$ & 6.1 & 0.96 \\
\hline OC & OC-S & $1.53(3 \%)$ & $1.07(18 \%)$ & 1.0 & 0.97 \\
& OC-SN & $1.51(5 \%)$ & $1.03(18 \%)$ & 9.9 & 0.94 \\
& HMOC & $1.49(5 \%)$ & $0.87(17 \%)$ & 1.2 & 0.99 \\
\hline \multirow{2}{*}{ EC } & LC-EC & $1.49(3 \%)$ & $1.35(11 \%)$ & 2.3 & 0.98 \\
& SC-EC & $1.47(3 \%)$ & $1.27(16 \%)$ & 10.6 & 0.96 \\
& NaK-EC & $1.53(4 \%)$ & $1.37(20 \%)$ & 6.6 & 0.98 \\
\hline \multirow{2}{*}{ Metal-rich } & Na-K & $1.51(4 \%)$ & $1.39(18 \%)$ & 7.2 & 0.97 \\
& Na-rich & $1.41(2 \%)$ & $1.41(11 \%)$ & 1.0 & 0.97 \\
& Cu-rich & $1.51(2 \%)$ & $1.39(11 \%)$ & 0.9 & 0.91 \\
& Pb-rich & $1.51(2 \%)$ & $1.49(14 \%)$ & 1.6 & 0.96 \\
& Fe-rich & $1.49(3 \%)$ & $1.29(17 \%)$ & 3.8 & 0.96 \\
& Cu-Pb-Fe & $1.47(5 \%)$ & $1.51(9 \%)$ & 1.2 & 0.96 \\
\hline
\end{tabular}

a The uncertainties for the retrieved $n$ and $\rho_{\text {eff }}$ estimated through the sensitivity analysis. ${ }^{\mathrm{b}}$ Percentage of a particle type detected relative to all the characterized particles. ${ }^{\mathrm{c}}$ Correlation coefficient between measured and best-fitting PSCS.

to the non-spherical particles that scattered less light, and also the higher uncertainty at smaller sizes associated with the calibration function (Fig. S2). A similar particle type OC-SN had similar $n(1.51)$ and $\rho_{\text {eff }}\left(1.03 \mathrm{~g} \mathrm{~cm}^{-3}\right)$ to that of OC-S (Fig. S4). The retrieved $\rho_{\text {eff }}$ is slightly lower than that for OC-S, probably attributed to slightly lower material density of nitrate compared to sulfate. Notably, HMOC had a lower $\rho_{\text {eff }}$ at $0.87 \mathrm{~g} \mathrm{~cm}^{-3}$, similarly observed in Mexico City (Moffet et al., 2008), indicative of a unique composition (Fig. 2). There were many peaks associated with higher mass-to-charge ratio in the mass spectra, rather than in those of OC-S and OC-SN. Low-density OC was also observed in biomass-burning aerosols $\left(0.9 \mathrm{~g} \mathrm{~cm}^{-3}\right)$ (Schkolnik et al., 2007) and ambient aerosols $\left(0.87-0.9 \mathrm{~g} \mathrm{~cm}^{-3}\right.$ ) (Spencer et al., 2007; Cross et al., 2009), attributed to a dominant proportion of aliphatic compounds in OC (Schkolnik et al., 2007). Overall, the retrieved $\rho_{\text {eff }}\left(0.87-1.07 \mathrm{~g} \mathrm{~cm}^{-3}\right)$ for these OC particle types are lower than those $\left(1.14-1.7 \mathrm{~g} \mathrm{~cm}^{-3}\right)$ in California and Mexico City (Moffet et al., 2008), which may reflect a different mixing state for $\mathrm{OC}$ with sulfate and/or nitrate in these areas. The lower densities for OC particle types in the present study may also indicate that they were mainly composed of organics rather than other species (i.e., nitrate and sulfate) with higher densities $\left(\sim 1.7 \mathrm{~g} \mathrm{~cm}^{-3}\right)$, and/or reflect less oxidized organics.
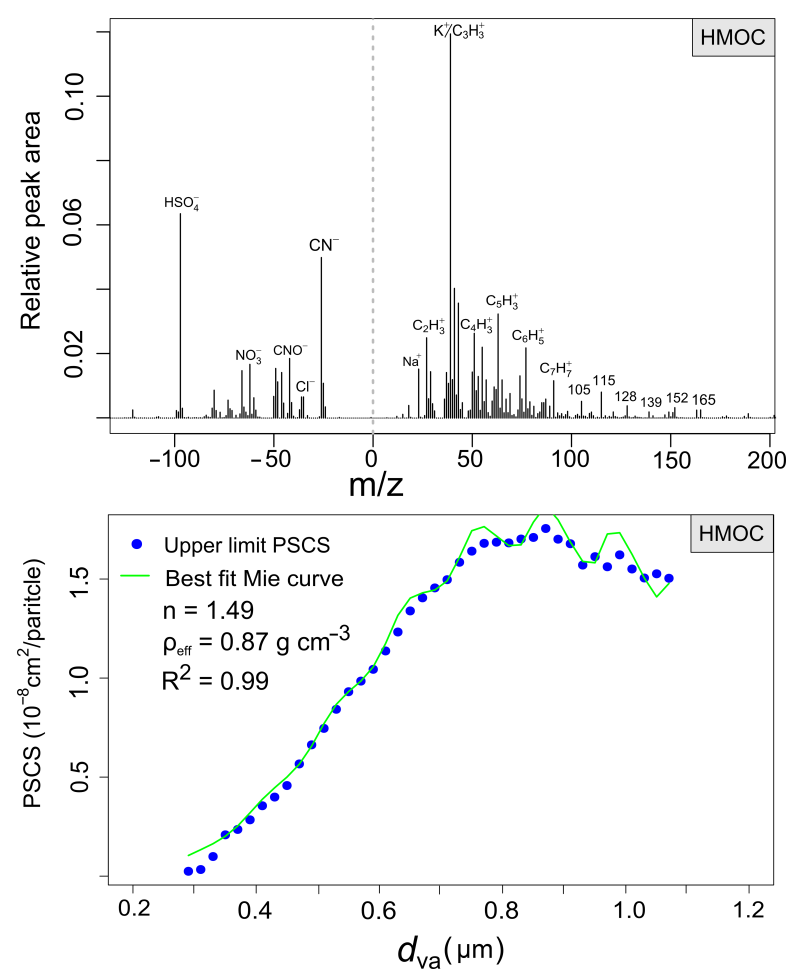

Figure 2. (top) Mass spectra, and (bottom) measured and best-fit theoretical PSCS for HMOC. 

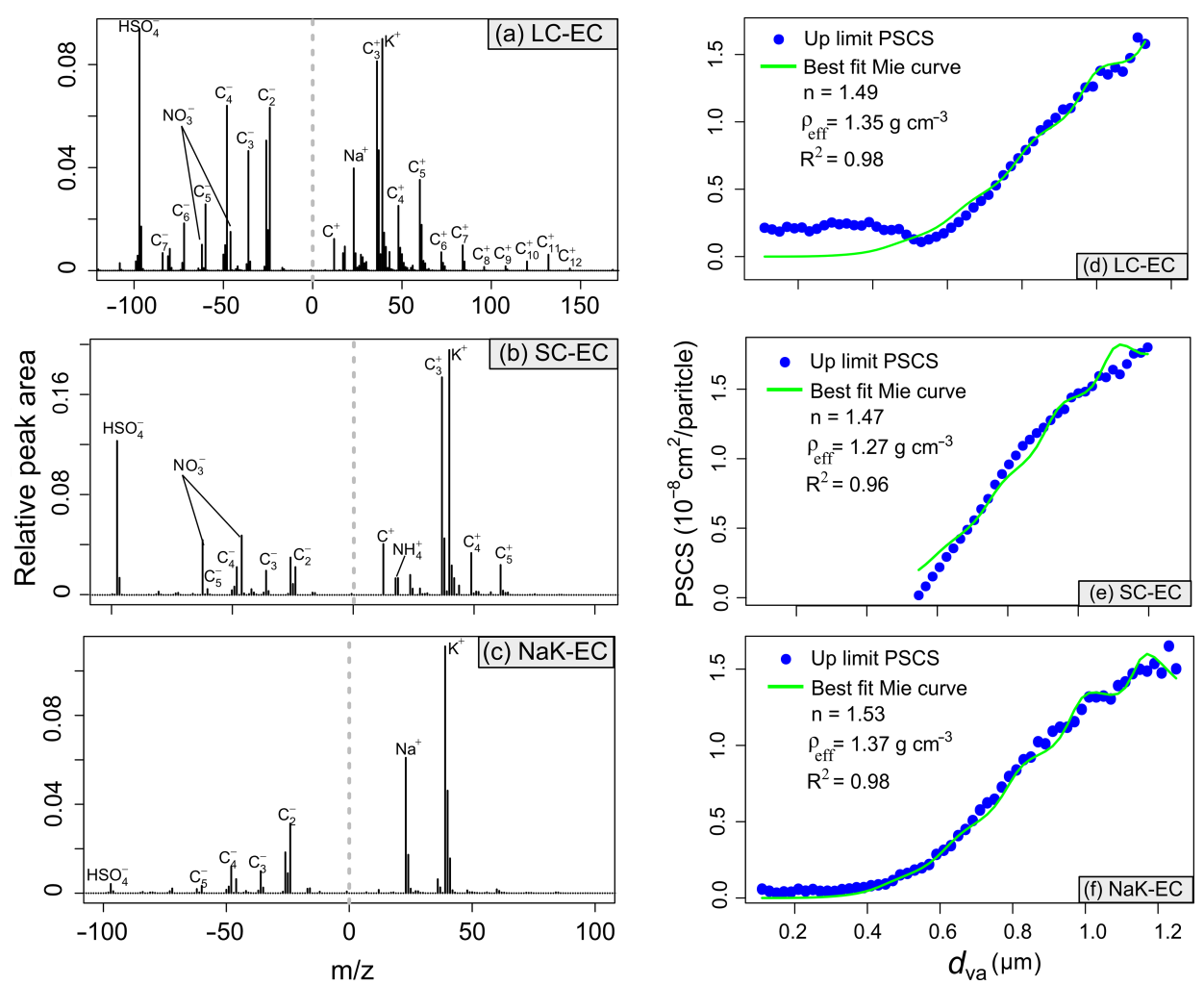

Figure 3. Mass spectra, and measured and best-fit theoretical PSCS for LC-EC, SC-EC, and NaK-EC, respectively.

\subsubsection{EC Group}

The EC group contained three particle types, consisting of EC with more carbon cluster ions $\left(\mathrm{C}_{n}^{+/-}, n>6\right)(\mathrm{LC}-\mathrm{EC})$ (Fig. 3a) in the mass spectra, EC with fewer carbon cluster ions $\left(\mathrm{C}_{n}^{+/-}, n<6\right)$ (SC-EC) (Fig. 3b), and EC accompanied by intense sodium and potassium ions peaks (NaK-EC, Fig. 3c). The mass spectra of these particle types are dominated by fragments from EC and associated with limited OC fraction. The PSCS plotted against $d_{\mathrm{va}}$ for them are shown in Fig. 3d-f. LC-EC has a complex scattering curve versus $d_{\mathrm{va}}$, which can be explained by the presence of both compact (i.e., more spherical) and irregular particles resulting from differences in particle age (Moffet et al., 2008). This type exhibited a scattering curve strongly deviating from the theoretical one in the size range of $0.1-0.5 \mu \mathrm{m}$, suggesting an irregular morphology. EC in this size range is typically observed to be of extremely low $\rho_{\text {eff }}\left(<1.0 \mathrm{~g} \mathrm{~cm}^{-3}\right)$ due to the open and fractal morphology (Levy et al., 2013; Zhang et al., 2008). However, the scattering curve for LC-EC of larger size is well fitted, implying the existence of a more spherical shape. This transformation from fractal to compact morphology could be explained by a mixing state with a secondary species, such as sulfate, nitrate, and ammonium (Zhang et al., 2008; Moffet and Prather, 2009). Although water may play a key role in the collapse of fractal morphology (Mikhailov et al., 2006), this issue cannot be addressed in the present study since the particles were dried before measurements. Pagels et al. (2009) illustrated that fresh soot has a highly irregular structure, while coated soot exhibits a considerable compaction. They also showed that considerable compaction of the particles occurred when they were heated or dried. We have previously shown that EC-containing particles tend to internally mix with a greater amount of secondary species with increasing size in the Pearl River Delta (PRD) region (Zhang et al., 2014). Differently, SC-EC particles were found to be internally mixed with much greater amount of secondary species, which could cause collapse of the fractal morphology (Zhang et al., 2008), and thus showed a betterfitted scattering curve. An interesting observation is that although associated with limited secondary species (Fig. 3c), the NaK-EC type was likely spherical over the detected size range, also showing a well-fitted scattering curve. The retrieved $n$ and $\rho_{\text {eff }}$ are 1.49 and $1.35 \mathrm{~g} \mathrm{~cm}^{-3}$ for LC-EC, 1.47 and $1.27 \mathrm{~g} \mathrm{~cm}^{-3}$ for SC-EC, and 1.53 and $1.37 \mathrm{~g} \mathrm{~cm}^{-3}$ for NaK-EC type. The retrieved $\rho_{\text {eff }}$ are lower than the material density of EC $\left(1.7-1.9 \mathrm{~g} \mathrm{~cm}^{-3}\right)$, due to the changing mixing state and shape factor (Bond and Bergstrom, 2006; Park et al., 2004). The retrieved $n$ for EC are lower than those observed for freshly emitted EC particles (e.g., 1.8-2) (Schmid et al., 2009; Schkolnik et al., 2007), which is probably attributed to internally mixed secondary coatings (having $n$ around 1.5) on the processed EC particle types (Moffet et al., 2008), as identified in their mass spectra (Fig. 3). 


\subsubsection{ECOC group}

The ECOC group contained both OC and EC ion signatures in the mass spectra, including potassium-rich particles internally mixed with sulfate/nitrate (K-S for dominantly with sulfate, K-N for dominantly with nitrate, and K-SN for both sulfate and nitrate), and ECOC internally mixed with sulfate/nitrate (ECOC-S and ECOC-SN). The retrieved $n$ is 1.47-1.49 for this particle group. From the well-fit scattering curves (Fig. S5), the retrieved $\rho_{\text {eff }}$ for K-N is $1.43 \mathrm{~g} \mathrm{~cm}^{-3}$, while the remaining particle types have much lower densities in a range of $1.21-1.27 \mathrm{~g} \mathrm{~cm}^{-3}$. This particle group containing some amount of EC and OC, internally mixing with secondary species, exhibits a complex of densities for these chemical compositions (Bond and Bergstrom, 2006; Schkolnik et al., 2007; Nakao et al., 2013). Much higher $\rho_{\text {eff }}$ for K-N particles might be explained by more spherical shape, with lower dynamic shape factor, since it is believed to be more aged than the other particle types, consistent with that observed in Mexico City (Moffet et al., 2008).

\subsubsection{Metal-rich group}

The Metal-rich group, including Na-rich, Na-K, Fe-rich, $\mathrm{Pb}$ rich, $\mathrm{Cu}$-rich, and internally mixed $\mathrm{Fe}-\mathrm{Cu}-\mathrm{Pb}$ types, also exhibits scattering curves that are indicative of the existence of nearly spherical morphology (Figs. 4 and S5). The retrieved $n$ is $1.47-1.51$ for this particle group, except for Narich (1.41) type. As expected, higher $\rho_{\text {eff }}\left(1.29-1.51 \mathrm{~g} \mathrm{~cm}^{-3}\right)$ were retrieved for these particle types (Table 1). The Narich type typically represents sea salt aerosols (Moffet et al., 2008). The retrieved $n$ and $\rho_{\text {eff }}$ are 1.41 and $1.41 \mathrm{~g} \mathrm{~cm}^{-3}$ for Na-rich type. Note that the detected Na-rich had experienced atmospheric aging during transport, evidenced by their mass spectra associated with high amount of nitrate rather than chloride (Gard et al., 1998). The retrieved $n$ for Na-rich particle type is slightly lower than that of a similar particle type (sea salt type, $n$ at 1.43-1.5) observed in California (Moffet et al., 2008). The Fe-rich, $\mathrm{Pb}$-rich, $\mathrm{Cu}$-rich, and $\mathrm{Cu}-\mathrm{Pb}-\mathrm{Fe}$ types were previously found to be externally mixed with carbonaceous species and were mainly attributed to emission from local/regional industries (Zhang et al., 2015b). In addition, it is noted that these Metal-rich types are mainly distributed in aerosols of larger size (i.e., $>0.5 \mu \mathrm{m}$ ), and thus the retrieved $n$ and $\rho_{\text {eff }}$ only represent such fraction rather than that of smaller size, which may only account for a negligible fraction (from less than 0.01 to $3.4 \%$ in this study) (Fig. 5).

\subsection{Comparison with previous studies and atmospheric implications}

The results show that the scattering curves for the majority of particle types can be well modeled (with $R^{2}$ greater than 0.95 ), suggesting the existence of spherical or nearly spherical shape. The majority of the particle types in the present
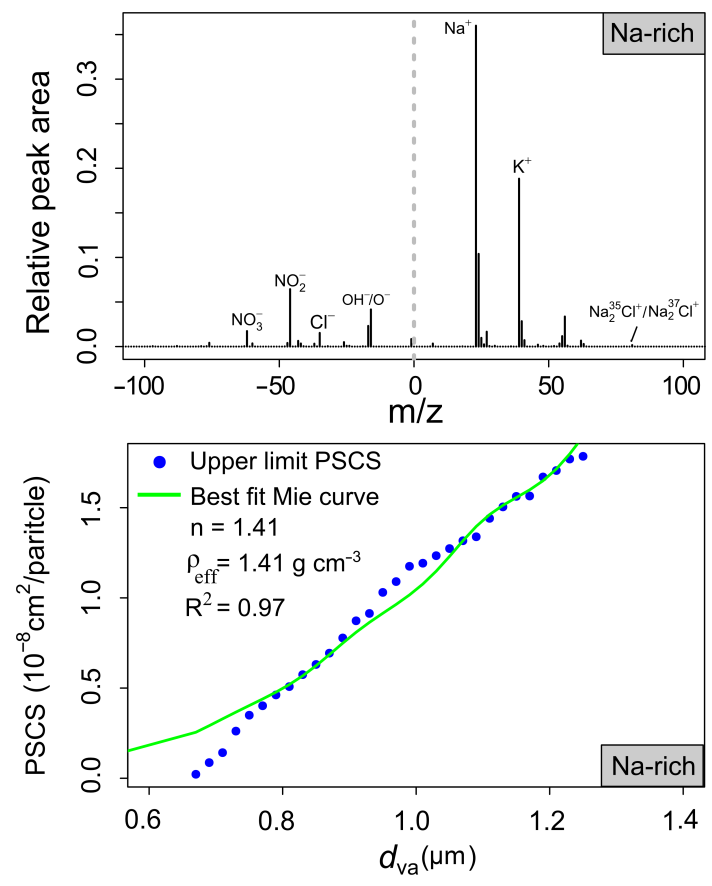

Figure 4. (top) Mass spectra and (bottom) measured and best-fit theoretical PSCS for Na-rich type.

study have $n$ around 1.5 (Table 1), consistent with those of the most abundant species (i.e., ammonium sulfate and organics), observed in the atmosphere of Guangzhou (Andreae et al., 2008). From combined Raman lidar and sunphotometer observations, Muller et al. (2006) retrieved $n$ at $1.57 \pm 0.11$ for the haze layer in a similar region. Moffet et al. (2008) showed that the majority of particle types in California exhibited very similar $n$ around 1.5, and concluded that the optical properties of these particle types are controlled by the condensation of secondary species. In contrast, the retrieved $\rho_{\text {eff }}$ is distributed in a wide range of $0.87-$ $1.51 \mathrm{~g} \mathrm{~cm}^{-3}$ in this study, indicative of a diverse distribution of aerosol population in the atmosphere of Guangzhou. High diversity rather than homogeneity in chemical compositions of atmospheric aerosols has also been highlighted in other regions worldwide (e.g., California and Mexico City), and is most likely related to the diversity of sources and differences in aging of the particles (Spencer et al., 2007; Roger et al., 2009; Pitz et al., 2008; Levy et al., 2013; Moffet et al., 2008). $\rho_{\text {eff }}$ was observed to be in a wide range in Mexico City (1.1$3.4 \mathrm{~g} \mathrm{~cm}^{-3}$ ) (Moffet et al., 2008), urban Augsburg, Germany $\left(1.05-2.36 \mathrm{~g} \mathrm{~cm}^{-3}\right)$ (Pitz et al., 2008), and from lower than $1.0 \mathrm{~g} \mathrm{~cm}^{-3}$ due to freshly emitted EC aerosols to as high as $1.8 \mathrm{~g} \mathrm{~cm}^{-3}$ in Texas, USA (Levy et al., 2013). In addition, size-resolved $\rho_{\text {eff }}$ is calculated based on the fractional contribution of each particle type as a function of $d_{\mathrm{va}}$ (Fig. 5). The trend of the estimated $\rho_{\text {eff }}$ is mainly attributed to the chemical diversity as a function of particle size (Barone et al., 2011; Hu et al., 2012). 


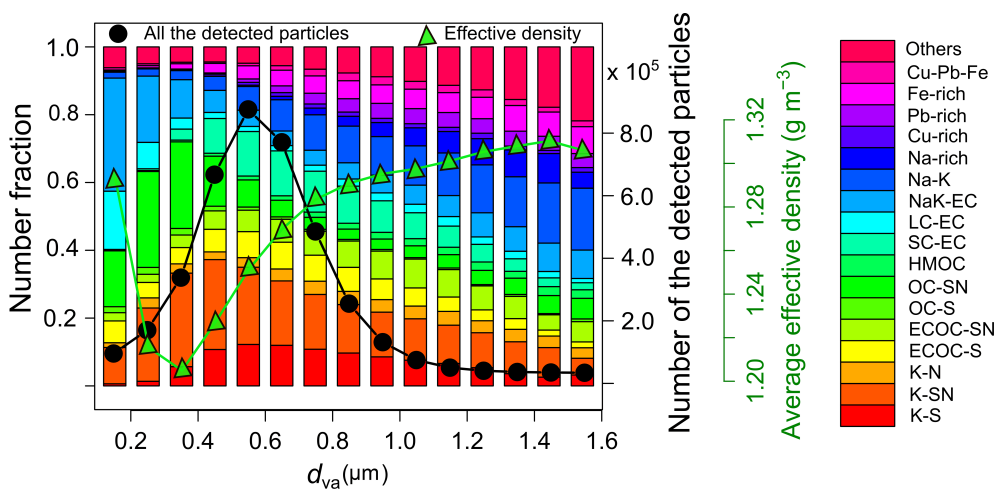

Figure 5. Number fraction, number of all the detected particles, and the estimated average $\rho_{\text {eff }}$ of each particle type as a function of $d_{\mathrm{va}}$.

For models that predict the radiative impact of aerosols, it is important to be able to constrain the $n$ and $\rho_{\text {eff }}$ of various aerosol components. While the $n$ of pure compositions are fairly well constrained, significant uncertainties exist regarding $n$ for the internally mixed aerosols (e.g., Bond and Bergstrom, 2006; Freedman et al., 2009). When an internal aerosol mixing state is incorporated into a global climate model, the most common way to determine optical properties is to volume-weight the refractive indices of aerosol constituents (Lesins et al., 2002; Ghan and Zaveri, 2007). Freedman et al. (2009) have noted that if species-specific refractive index is used, rather than a volume-weighted average refractive index, then the deviation from the average value could cause a significant difference in radiative forcing. Our results by direct observation on single particle types provide a reference of particle type specific $n$ and $\rho_{\text {eff }}$ for further studies on light extinction, or the radiative forcing of atmospheric aerosol in the PRD region. A limitation of our study mainly relates to the derivation of the scattering curve from the upper limit of a specific particle type, which represents the ideal case of interaction between spherical particles and the laser beam of SPAMS. As a result, the remaining particles, including irregularly shaped particles, were not well characterized, although shape is regarded as a potentially important variable in radiative forcing (Adachi et al., 2010). Another limitation may be associated with the assumption that the $\rho_{\text {eff }}$ for each particle type was identical in all the sizes in the estimation of size-resolved $\rho_{\text {eff }}$, since $\rho_{\text {eff }}$ is not only dependent on chemical composition, but also particle morphology (Hu et al., 2012). Additionally, ambient aerosols were first dried before any measurements in the present study, and thus possible differences may exist for refractive indices when water is included (Eichler et al., 2008; Dick et al., 2007). The amount of water taken up by water-soluble particle matter changes the particle size distributions and their refractive index, and hence also plays an important role in both visibility impairment and aerosol radiative forcing.

\section{Conclusions}

The size, mass spectra information, and light-scattering signals were simultaneously obtained for chemically segregated ambient aerosols in the atmosphere of Guangzhou, China. Based on comparison between experimental light-scattering measurements obtained by a SPAMS and Mie theoretical calculation results, $n$ and $\rho_{\text {eff }}$ of 17 particle types in four particle categories, including OC, EC, ECOC, and Metal-rich groups, were retrieved. The majority of the particle types could be well modeled under the assumption that particles are homogeneously internally mixed, with a spherical or nearly spherical shape. The retrieved $n$ for the majority of particle types range from 1.47 to 1.53 . However, $\rho_{\mathrm{eff}}$ were observed in a wide range of $0.87-1.51 \mathrm{~g} \mathrm{~cm}^{-3}$, suggesting a chemical diversity of aerosol population. Interestingly, EC types of different mixing state showed different microphysical characteristics, which indicates that more detailed observations and simulations are needed for particle types of different age to constrain the assumptions of their $n$ and $\rho_{\text {eff }}$ in radiative impact modeling. This work improves the understanding of the microphysical properties of individual particles in the urban atmosphere in China, and also provides a reference for assumptions of $n$ and $\rho_{\text {eff }}$ for various aerosol components.

\section{The Supplement related to this article is available online at doi:10.5194/acp-16-2631-2016-supplement.}

Acknowledgements. The authors acknowledge financial support from the "Strategic Priority Research Program (B)" of the Chinese Academy of Sciences (XDB05020205), the National Nature Science Foundation of China (No. 41405131 and 41403091) and the Foundation for Leading Talents from Guangdong Province Government.

Edited by: A. Hofzumahaus 


\section{References}

Adachi, K., Chung, S. H., and Buseck, P. R.: Shapes of soot aerosol particles and implications for their effects on climate, J. Geophys. Res.-Atmos., 115, 4447-4458, doi:10.1029/2009jd012868, 2010.

Andreae, M. O., Schmid, O., Yang, H., Chand, D. L., Yu, J. Z., Zeng, L. M., and Zhang, Y. H.: Optical properties and chemical composition of the atmospheric aerosol in urban Guangzhou, China, Atmos. Environ., 42, 6335-6350, doi:10.1016/j.atmosenv.2008.01.030, 2008.

Barone, T. L., Lall, A. A., Storey, J. M. E., Mulholland, G. W., Prikhodko, V. Y., Frankland, J. H., Parks, J. E., and Zachariah, M. R.: Size-Resolved Density Measurements of Particle Emissions from an Advanced Combustion Diesel Engine: Effect of Aggregate Morphology, Energy Fuels, 25, 1978-1988, doi:10.1021/Ef200084k, 2011.

Bauer, S. E., Ault, A., and Prather, K. A.: Evaluation of aerosol mixing state classes in the GISS modelE-MATRIX climate model using single-particle mass spectrometry measurements, J. Geophys. Res.-Atmos., 118, 9834-9844, doi:10.1002/jgrd.50700, 2013.

Bi, X. H., Zhang, G. H., Li, L., Wang, X. M., Li, M., Sheng, G. Y., Fu, J. M., and Zhou, Z.: Mixing state of biomass burning particles by single particle aerosol mass spectrometer in the urban area of PRD, China, Atmos. Environ., 45, 3447-3453, doi:10.1016/j.atmosenv.2011.03.034, 2011.

Bohren, C. F. and Huffman, D. R.: Absorption and scattering of light by small particles, John Wiley \&Sons, Inc., New York, 1981.

Bond, T. C. and Bergstrom, R. W.: Light absorption by carbonaceous particles: An investigative review, Aerosol Sci. Tech., 40, 27-67, doi:10.1080/02786820500421521, 2006.

Cross, E. S., Slowik, J. G., Davidovits, P., Allan, J. D., Worsnop, D. R., Jayne, J. T., Lewis, D. K., Canagaratna, M., and Onasch, T. B.: Laboratory and ambient particle density determinations using light scattering in conjunction with aerosol mass spectrometry, Aerosol Sci. Tech., 41, 343-359, doi:10.1080/02786820701199736, 2007.

Cross, E. S., Onasch, T. B., Canagaratna, M., Jayne, J. T., Kimmel, J., Yu, X.-Y., Alexander, M. L., Worsnop, D. R., and Davidovits, P.: Single particle characterization using a light scattering module coupled to a time-of-flight aerosol mass spectrometer, Atmos. Chem. Phys., 9, 7769-7793, doi:10.5194/acp-9-7769-2009, 2009.

Dick, W. D., Ziemann, P. J., and McMurry, P. H.: Multiangle Light-Scattering Measurements of Refractive Index of Submicron Atmospheric Particles, Aerosol Sci. Tech., 41, 549-569, doi:10.1080/02786820701272012, 2007.

Eichler, H., Cheng, Y. F., Birmili, W., Nowak, A., Wiedensohler, A., Brüggemann, E., Gnauk, T., Herrmann, H., Althausen, D., Ansmann, A., Engelmann, R., Tesche, M., Wendisch, M., Zhang, Y. H., Hu, M., Liu, S., and Zeng, L. M.: Hygroscopic properties and extinction of aerosol particles at ambient relative humidity in South-Eastern China, Atmos. Environ., 42, 6321-6334, doi:10.1016/j.atmosenv.2008.05.007, 2008.

Freedman, M. A., Hasenkopf, C. A., Beaver, M. R., and Tolbert, M. A.: Optical Properties of Internally Mixed Aerosol Particles Composed of Dicarboxylic Acids and Ammonium Sulfate, J. Phys. Chem. A, 113, 13584-13592, doi:10.1021/jp906240y, 2009.
Gard, E. E., Kleeman, M. J., Gross, D. S., Hughes, L. S., Allen, J. O., Morrical, B. D., Fergenson, D. P., Dienes, T., Galli, M. E., Johnson, R. J., Cass, G. R., and Prather, K. A.: Direct observation of heterogeneous chemistry in the atmosphere, Science, 279, 1184-1187, doi:10.1126/science.279.5354.1184, 1998.

Ghan, S. J. and Schwartz, S. E.: Aerosol properties and processes - A path from field and laboratory measurements to global climate models, B. Am. Meteorol. Soc., 88, 1059-1083, doi:10.1175/Bams-88-7-1059, 2007.

Ghan, S. J. and Zaveri, R. A.: Parameterization of optical properties for hydrated internally mixed aerosol, J. Geophys. Res.-Atmos., 112, 185-194, 2007.

Hand, J. L. and Kreidenweis, S. M.: A new method for retrieving particle refractive index and effective density from aerosol size distribution data, Aerosol Sci. Tech., 36, 1012-1026, 2002.

Hu, M., Peng, J. F., Sun, K., Yue, D. L., Guo, S., Wiedensohler, A., and $\mathrm{Wu}, \mathrm{Z}$. J.: Estimation of Size-Resolved Ambient Particle Density Based on the Measurement of Aerosol Number, Mass, and Chemical Size Distributions in the Winter in Beijing, Environ. Sci. Technol., 46, 9941-9947, doi:10.1021/Es204073t, 2012.

IPCC: Intergovernmental Panel on Climate Change, Climate Change 2007: The Physical Science Basis AR4, Cambridge University Press, New York, 2007.

Jacobson, M. Z.: Strong radiative heating due to the mixing state of black carbon in atmospheric aerosols, Nature, 409, 695-697, 2001.

Jacobson, M. Z.: Effects of externally-through-internally-mixed soot inclusions within clouds and precipitation on global climate, J. Phys. Chem. A, 110, 6860-6873, doi:10.1021/Jp056391r, 2006.

Lesins, G., Chylek, P., and Lohmann, U.: A study of internal and external mixing scenarios and its effect on aerosol optical properties and direct radiative forcing, J. Geophys. Res.-Atmos., 107, 4094, doi:10.1029/2001jd000973, 2002.

Levy, M. E., Zhang, R. Y., Khalizov, A. F., Zheng, J., Collins, D. R., Glen, C. R., Wang, Y., Yu, X. Y., Luke, W., Jayne, J. T., and Olaguer, E.: Measurements of submicron aerosols in Houston, Texas during the 2009 SHARP field campaign, J. Geophys. Res.Atmos., 118, 10518-10534, doi:10.1002/Jgrd.50785, 2013.

Li, L., Huang, Z. X., Dong, J. G., Li, M., Gao, W., Nian, H. Q., Fu, Z., Zhang, G. H., Bi, X. H., Cheng, P., and Zhou, Z.: Real time bipolar time-of-flight mass spectrometer for analyzing single aerosol particles, Intl. J. Mass. Spectrom., 303, 118-124, doi:10.1016/j.ijms.2011.01.017, 2011.

Ma, N., Zhao, C. S., Müller, T., Cheng, Y. F., Liu, P. F., Deng, Z. Z., Xu, W. Y., Ran, L., Nekat, B., van Pinxteren, D., Gnauk, T., Müller, K., Herrmann, H., Yan, P., Zhou, X. J., and Wiedensohler, A.: A new method to determine the mixing state of light absorbing carbonaceous using the measured aerosol optical properties and number size distributions, Atmos. Chem. Phys., 12, 23812397, doi:10.5194/acp-12-2381-2012, 2012.

Mikhailov, E. F., Vlasenko, S. S., Podgorny, I. A., Ramanathan, V., and Corrigan, C. E.: Optical properties of soot-water drop agglomerates: An experimental study, J. Geophys. Res.-Atmos., 111, D07209, doi:10.1029/2005JD006389, 2006.

Moffet, R. C. and Prather, K. A.: Extending ATOFMS measurements to include refractive index and density, Anal. Chem., 77, 6535-6541, 2005. 
Moffet, R. C. and Prather, K. A.: In-situ measurements of the mixing state and optical properties of soot with implications for radiative forcing estimates, P. Natl. Acad. Sci. USA, 106, 1187211877, doi:10.1073/pnas.0900040106, 2009.

Moffet, R. C., Qin, X. Y., Rebotier, T., Furutani, H., and Prather, K. A.: Chemically segregated optical and microphysical properties of ambient aerosols measured in a singleparticle mass spectrometer, J. Geophys. Res.-Atmos., 113, 1-11, doi:10.1029/2007jd009393, 2008.

Muller, D., Tesche, M., Eichler, H., Engelmann, R., Althausen, D., Ansmann, A., Cheng, Y. F., Zhang, Y. H., and Hu, M.: Strong particle light absorption over the Pearl River Delta (south China) and Beijing (north China) determined from combined Raman lidar and Sun photometer observations, Geophys. Res. Lett., 33, L20811, doi:10.1029/2006g1027196, 2006.

Murphy, D. M., Cziczo, D. J., Hudson, P. K., Schein, M. E., and Thomson, D. S.: Particle density inferred from simultaneous optical and aerodynamic diameters sorted by composition, J. Aerosol Sci., 35, 135-139, doi:10.1016/S0021-8502(03)00386$0,2004$.

Myhre, G., Stordal, F., Restad, K., and Isaksen, I. S. A.: Estimation of the direct radiative forcing due to sulfate and soot aerosols, Tellus B, 50, 463-477, doi:10.1034/j.1600-0889.1998.t01-400005.x, 1998.

Nakao, S., Tang, P., Tang, X., Clark, C. H., Qi, L., Seo, E., Asa-Awuku, A., and Cocker Iii, D.: Density and elemental ratios of secondary organic aerosol: Application of a density prediction method, Atmos. Environ., 68, 273-277, doi:10.1016/j.atmosenv.2012.11.006, 2013.

Pagels, J., Khalizov, A. F., McMurry, P. H., and Zhang, R. Y.: Processing of Soot by Controlled Sulphuric Acid and Water CondensationMass and Mobility Relationship, Aerosol Sci.Tech., 43, 629-640, 2009.

Park, K., Kittelson, D. B., Zachariah, M. R., and McMurry, P. H.: Measurement of inherent material density of nanoparticle agglomerates, J. Nanopart. Res., 6, 267-272, doi:10.1023/B:Nano.0000034657.71309.E6, 2004.

Pitz, M., Schmid, O., Heinrich, J., Birmili, W., Maguhn, J. r., Zimmermann, R., Wichmann, H. E., Peters, A., and Cyrys, J.: Seasonal and Diurnal Variation of $\mathrm{PM}_{2.5}$ Apparent Particle Density in Urban Air in Augsburg, Germany, Environ. Sci. Technol., 42, 5087-5093, doi:10.1021/es7028735, 2008.

Ramanathan, V. and Carmichael, G.: Global and regional climate changes due to black carbon, Nat. Geosci., 1, 221-227, doi:10.1038/Ngeo156, 2008.

Raut, J. C., Chazette, P., and Fortain, A.: Link between aerosol optical, microphysical and chemical measurements in an underground railway station in Paris, Atmos. Environ., 43, 860-868, 2009.

Roger, J. C., Guinot, B., Cachier, H., Mallet, M., Dubovik, O., and Yu, T.: Aerosol complexity in megacities: From sizeresolved chemical composition to optical properties of the Beijing atmospheric particles, Geophys. Res. Lett., 36, L18806, doi:10.1029/2009GL039238, 2009.

Rosenfeld, D., Lohmann, U., Raga, G. B., O’Dowd, C. D., Kulmala, M., Fuzzi, S., Reissell, A., and Andreae, M. O.: Flood or drought: How do aerosols affect precipitation?, Science, 321, 1309-1313, doi:10.1126/science.1160606, 2008.
Schkolnik, G., Chand, D., Hoffer, A., Andreae, M. O., Erlick, C., Swietlicki, E., and Rudich, Y.: Constraining the density and complex refractive index of elemental and organic carbon in biomass burning aerosol using optical and chemical measurements, Atmos. Environ., 41, 1107-1118, 2007.

Schmid, O., Chand, D., Karg, E., Guyon, P., Frank, G. P., Swietlicki, E., and Andreae, M. O.: Derivation of the Density and Refractive Index of Organic Matter and Elemental Carbon from Closure between Physical and Chemical Aerosol Properties, Environ. Sci. Technol., 43, 1166-1172, doi:10.1021/es800570p, 2009.

Seinfeld, J. H. and Pandis, S. N.: Atmospheric Chemistry and Physics: From Air Pollution to Climate Change, edited by: John Wiley\&Sons, I., John Wiley\&Sons, Inc., New Jersey, 2006.

Shi, Y., Chen, J., Hu, D., Wang, L., Yang, X., and Wang, X.: Airborne submicron particulate $\left(\mathrm{PM}_{1}\right)$ pollution in Shanghai, China: Chemical variability, formation/dissociation of associated semivolatile components and the impacts on visibility, Sci. Total. Environ., 473-474, 199-206, doi:10.1016/j.scitotenv.2013.12.024, 2014.

Song, X. H., Hopke, P. K., Fergenson, D. P., and Prather, K. A.: Classification of single particles analyzed by ATOFMS using an artificial neural network, ART-2A, Anal. Chem., 71, 860-865, 1999.

Spencer, M. T., Shields, L. G., and Prather, K. A.: Simultaneous measurement of the effective density and chemical composition of ambient aerosol particles, Environ. Sci. Technol., 41, 13031309, 2007.

Sullivan, R. C. and Prather, K. A.: Recent advances in our understanding of atmospheric chemistry and climate made possible by on-line aerosol analysis instrumentation, Anal. Chem., 77, 38613885, 2005.

Tao, J., Zhang, L., Ho, K., Zhang, R., Lin, Z., Zhang, Z., Lin, M., Cao, J., Liu, S., and Wang, G.: Impact of $\mathrm{PM}_{2.5}$ chemical compositions on aerosol light scattering in Guangzhou - the largest megacity in South China, Atmos. Res., 135-136, 48-58, doi:10.1016/j.atmosres.2013.08.015, 2014.

Wu, D., Tie, X. X., Li, C. C., Ying, Z. M., Lau, A. K. H., Huang, J., Deng, X. J., and Bi, X. Y.: An extremely low visibility event over the Guangzhou region: A case study, Atmos. Environ., 39, 6568-6577, doi:10.1016/j.atmosenv.2005.07.061, 2005.

Zelenyuk, A., Imre, D., and Cuadra-Rodriguez, L. A.: Evaporation of water from particles in the aerodynamic lens inlet: An experimental study, Anal. Chem., 78, 6942-6947, 2006.

Zhang, G. H., Bi, X. H., He, J. J., Chen, D. H., Chan, L. Y., Xie, G. W., Wang, X. M., Sheng, G. Y., Fu, J. M., and Zhou, Z.: Variation of secondary coatings associated with elemental carbon by single particle analysis, Atmos. Environ., 92, 162-170, doi:10.1016/j.atmosenv.2014.04.018, 2014.

Zhang, G. H., Bi, X., Han, B., Qiu, N., Dai, S., Wang, X., Sheng, G., and $\mathrm{Fu}, \mathrm{J} .:$ Measurement of aerosol effective density by single particle mass spectrometry, Science China Earth Sciences, 59, 320-327, doi:10.1007/s11430-015-5146-y, 2015a.

Zhang, G. H., Han, B. X., Bi, X. H., Dai, S. H., Huang, W., Chen, D. H., Wang, X. M., Sheng, G. Y., Fu, J. M., and Zhou, Z.: Characteristics of individual particles in the atmosphere of Guangzhou by single particle mass spectrometry, Atmos. Res., 153, 286-295, doi:10.1016/j.atmosres.2014.08.016, 2015b. 
Zhang, Q. H., Zhang, J. P., and Xue, H. W.: The challenge of improving visibility in Beijing, Atmos. Chem. Phys., 10, 78217827, doi:10.5194/acp-10-7821-2010, 2010.
Zhang, R. Y., Khalizov, A. F., Pagels, J., Zhang, D., Xue, H. X., and McMurry, P. H.: Variability in morphology, hygroscopicity, and optical properties of soot aerosols during atmospheric processing, P. Natl. Acad. Sci. USA, 105, 10291-10296, doi:10.1073/pnas.0804860105, 2008. 